\title{
A metagenomic study of the microbial communities in four parallel biogas reactors
}

\author{
Linn Solli ${ }^{1}$, Othilde Elise Håvelsrud ${ }^{2}$, Svein Jarle Horn ${ }^{3^{*}}$ and Anne Gunn Rike ${ }^{4}$
}

\begin{abstract}
Background: Biogas is a renewable energy carrier which is used for heat and power production or, in the form of purified methane, as a vehicle fuel. The formation of methane from organic materials is carried out by a mixed microbial community under anaerobic conditions. However, details about the microbes involved and their function are limited. In this study we compare the metagenomes of four parallel biogas reactors digesting a protein-rich substrate, relate microbiology to biogas performance, and observe differences in these reactors' microbial communities compared to the original inoculum culture.

Results: The biogas process performance during the startup phase of four parallel continuous stirred tank reactors (designated R1, R2, R3, and R4) co-digesting fish waste and cow manure was studied. The microbial composition of the inoculum (day 0) and the four reactors at day 59 was studied and compared using 454 FLX Titanium pyrosequencing. In the inoculum and the reactor samples, the Bacteria Clostridium and Syntrophomonas were highly abundant, and the dominating methanogen was the hydrogenotrophic Methanoculleus. Syntrophic prokaryotes frequently found in biogas reactors with high concentrations of ammonium and volatile fatty acids were detected in all samples. The species Candidatus Cloacimonas acidaminovorans of the candidate phylum Cloacimonetes (WWE1) increased in all reactors and was the dominating bacterium at day 59. In particular, this bacterium showed a very high abundance in R1, which distinguished this reactor significantly from the other reactors in terms of microbial composition. Methane production and the reactor slurry characteristics were monitored in the digestion period. Generally all four reactors operated stably and showed rather similar characteristics. The average methane production in the reactors varied between 0.278 and $0.296 \mathrm{~L} \mathrm{gVS}^{-1}$, with the lowest production in R1.

Conclusions: This study showed that four parallel reactors co-digesting manure and fish waste silage operated stably during a startup phase. Several important Archaea and Bacteria degrading the protein-rich substrate were identified. In particular, microorganisms involved in syntrophic methane production seemed to be important. The detailed characterization of the microbial communities presented in this work may be useful for the operation of biogas plants degrading substrates with high concentrations of proteins.
\end{abstract}

Keywords: Anaerobic digestion, Syntrophic oxidation, Metagenomic, Biogas, Taxonomic structure, Biofuel, Biorefinery, Methane

\section{Background}

Anaerobic digestion of organic materials from agriculture and industry may reduce local pollution and provide energy in the form of methane. Large amounts of organic materials are produced and disposed as waste every year. In Norway organic materials such as cattle manure and dead fish from fish farms are in large supply. In 2012 a

\footnotetext{
*Correspondence: svein.horn@nmbu.no

${ }^{3}$ Department of Chemistry, Biotechnology and Food Science, Norwegian University of Life Sciences, P.O. Box 5003, N-1432, Ås, Norway

Full list of author information is available at the end of the article
}

loss of 27.4 million dead salmon was reported from Norwegian fish farms [1], and the total annual amount of organic waste in Norway is 1.45 million tons [2].

During anaerobic digestion organic materials are converted to methane and carbon dioxide plus small amounts of other gases by a microbial community through four main reactions: hydrolysis, acidogenesis, acetogenesis, and methanogenesis. The anaerobic degradation process is initiated by hydrolysis, where complex molecules like carbohydrates, lipids, and proteins are depolymerized into soluble compounds by a range of enzymes produced by 
the Bacteria. The hydrolyzed compounds are further fermented into acetate, propionate, butyrate, lactate, ethanol, methanol, ammonia, hydrogen, and carbon dioxide. Acetogenesis is the reaction in which acetate is produced from hydrogen and carbon sources by acetogenic Bacteria [3].

Methanogens belong to the Archaeal phylum Euryarchaeota [4], and methane is produced in the last step of the anaerobic process. The methane-producing microorganisms that usually dominate in biogas reactors are the acetoclastic methanogens [5]. The acetoclastic pathway is carried out by the order Methanosarcinales [6,7]. The primary substrate for methane production by the hydrogenotrophic methanogens is $\mathrm{CO}_{2}$ and $\mathrm{H}_{2}$, and this group consists of several methanogenic orders: Methanobacteriales, Methanococcales, and Methanomicrobiales [6,7]. An alternative methane production pathway, called syntrophic acetate oxidation, is known to take place in reactors with a high content of ammonia and fatty acids. The reaction includes conversion of acetate to $\mathrm{H}_{2}$ and $\mathrm{CO}_{2}$ by syntrophic acetate-oxidizing Bacteria, such as Clostridium ultunense, Tepidanaerobacter acetatoxydans, and Syntrophaceticus schinkii, followed by methane production by a hydrogenotrophic methanogen (for example, members of the orders Methanomicrobiales and Methanobacteriales) [8-11].

The acetogenic Bacteria and the methanogenic Archaea differ largely in terms of nutritional needs and sensitivity to environmental conditions [12]. Additionally, the methanogens have a slower growth rate than the acidogenic Bacteria [13], which in turn may result in accumulation of intermediate degradation products. A common reason for biogas reactor instability is failure to maintain the balance between these two groups of microorganisms [14].

The various complex anaerobic reactions that lead to methane formation are to a large extent performed through syntrophy between Bacteria and methanogenic Archaea. These syntrophic relationships provide the methanogens with their substrates and remove metabolic products from the acid-forming Bacteria [15]. Analyses of microbial communities have shown that elevated concentrations of ammonia in biogas reactors trigger the syntrophic acetate oxidation pathway, where acetate is transformed to $\mathrm{CO}_{2}$ and $\mathrm{H}_{2}$ before methane is produced by hydrogenotrophic methanogens $[8,9]$. The syntrophic degradation of other short chain fatty acids during anaerobic digestion has also been described [16,17], and several Bacterial strains and groups of methanogens are identified as having key roles in various syntrophic reactions.

Ensilaged fish waste contains large amounts of fat and protein [1], making it an energy-rich substrate that is suitable for biogas production. However, high inputs of fat and protein to a biogas reactor may cause accumulation of ammonia and fatty acids, potentially yielding unstable methane production and biogas reactor failure
$[15,18]$. Generally, methanogens, and thus methane production, are inhibited by ammonia $\left(\mathrm{NH}_{3}\right)$ formed in the process of protein degradation [19-21]. Long chain fatty acids (LCFAs) [22] and volatile fatty acids (VFAs) [23] formed from lipid degradation may also lead to inhibition.

The low $\mathrm{pH}$ of the ensilaged fish waste and the high concentrations of fat and protein make the substrate suitable for co-digestion with an alkaline organic material like cow manure. Co-digestion may improve the anaerobic digestion process by creating a better nutrient balance, diluting toxic compounds, and stimulating synergistic effects of microorganisms [24-26], and may possibly also increase the stability of the system and the methane production.

The startup is a critical phase in biogas reactors $[13,27,28]$, and inoculum stability is highly important. Anaerobic microbial communities can adapt to high concentrations of ammonia and fatty acids [29], if a strategy of gradual acclimatization and proper adjustment of operational parameters such as substrate composition, organic loading rate (OLR), and hydraulic retention time (HRT) is applied [30]. During startup of a biogas reactor, many different groups of microorganisms with varying requirements for biochemical and physical conditions are introduced, and the initial one to three weeks are considered to be a reactor's startup period [13]. Several experiments have dealt with startup dynamics in anaerobic digestion [13,31,32], but to our best knowledge, no metagenome analyses of microbial community structure in parallel continuously stirred tank reactors (CSTR) have been carried out.

The objectives of this study were to use metagenomic sequencing analysis to examine the microbial composition of a methane-producing inoculum, and to investigate the development of the inoculum through a stabilization period of 59 days in four parallel biogas reactors added proteinrich substrate under mesophilic conditions. The goal was also to compare the four reactors to investigate if the development of the microbial communities was similar in reactors running under the same conditions.

\section{Results and discussion}

\section{Methane production and reactor slurry characteristics}

The performance of four parallel biogas reactors during semicontinuous addition of fat and protein-rich materials (Table 1 ) was studied (Figure 1). The biogas volume and the $\mathrm{CH}_{4}$ and $\mathrm{CO}_{2}$ concentrations were measured once a day. In Figure 1A the average methane production is shown every fourth day. Although the $\mathrm{CH}_{4}$ production was quite similar in the four reactors, a somewhat lower $\mathrm{CH}_{4}$ production was observed from day 47 for $\mathrm{R} 1$. The average values of methane production in R1 and R2 were $0.282( \pm 0.039)$ and $0.297( \pm 0.042) \mathrm{L} \mathrm{gVS}^{-1}$, respectively (Figure 1A). These $\mathrm{CH}_{4}$ yields are in accordance with 
Table 1 Chemical characterization of reactors' substrate

\begin{tabular}{|c|c|c|c|c|c|c|c|c|}
\hline Dry matter (\%) & $\begin{array}{l}\text { Volatile } \\
\text { solids* (\%) }\end{array}$ & $\begin{array}{l}\text { Total nitrogen } \\
\left(\mathrm{g} \mathrm{L}^{-1}\right)\end{array}$ & $\begin{array}{l}\text { Total carbon } \\
\left(\mathrm{g} \mathrm{L}^{-1}\right)\end{array}$ & Carbon/nitrogen & $\begin{array}{l}\text { Acetic acid } \\
\left(\mathrm{g} \mathrm{L}^{-1}\right)\end{array}$ & $\begin{array}{l}\text { Propionic } \\
\text { acid }\left(\mathrm{g} \mathrm{L}^{-1}\right)\end{array}$ & $\begin{array}{l}\text { Ammonium } \\
\left(\mathrm{g} \mathrm{L}^{-1}\right)\end{array}$ & $\mathrm{pH}$ \\
\hline 2 & 84.1 & 4.06 & 47.09 & 11.80 & 2.88 & 1.69 & 2.90 & 6.20 \\
\hline
\end{tabular}

*Percentage of dry matter.

previous experiments on anaerobic co-digestion of the same substrates, where the yield was between 0.250 and $0.300 \mathrm{~L} \mathrm{CH}_{4} \mathrm{gVS}^{-1}$ [1]. The production of $\mathrm{CO}_{2}$ in the four reactors was on average between 0.142 and $0.161 \mathrm{~L} \mathrm{CO}_{2}$ $\mathrm{gVS}^{-1}$ during the experiment (data not shown).
The $\mathrm{NH}_{4}{ }^{+}$, VFA, $\mathrm{pH}$, and volatile solids (VS) reductions were measured every fourth day during the experimental period. The $\mathrm{pH}$ was around 8 in all the reactors during the entire period (Figure $1 \mathrm{C}$ ). The average $\mathrm{NH}_{4}{ }^{+}$ concentrations were highest in $\mathrm{R} 1$, with a concentration

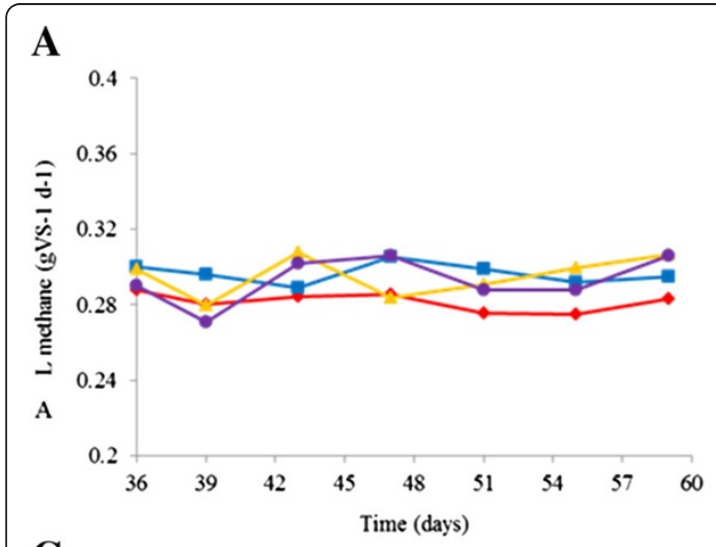

C
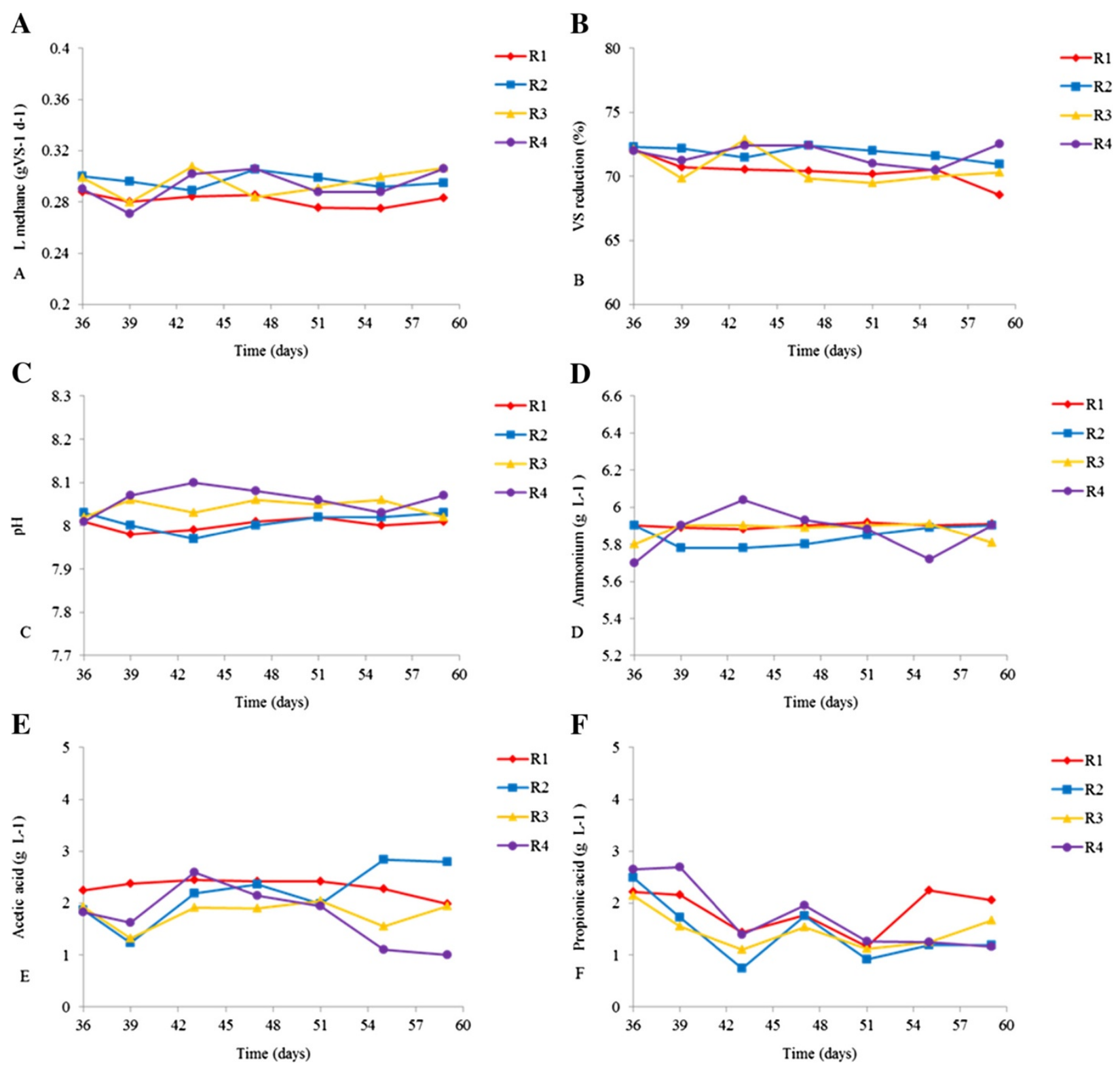

Figure 1 Anaerobic process performance in R1, R2, R3, and R4 during 28 days of continuous operation (day 36 to day 59). A) Methane productions, B) \% volatile solid (VS) removal, C) pH values, D) $\mathrm{NH}_{4}{ }^{+}$concentrations, E) acetic acid concentration, and F) propionic acid concentration. 
of $5.90( \pm 0.08) \mathrm{g} \mathrm{L}^{-1}$, and lowest in $\mathrm{R} 2$, with a value of $5.84( \pm 0.042) \mathrm{g} \mathrm{L}^{-1}$ (Figure 1D), with corresponding $\mathrm{NH}_{3}$ concentrations in the range 0.67 to $0.75 \mathrm{~g} \mathrm{~L}^{-1}$ (data not shown). Previous experiments show that inhibition of methane production has been reported to take place at $\mathrm{NH}_{3}$ concentrations of 0.7 to $2.0 \mathrm{~g} \mathrm{~L}^{-1}[19,29,33,34]$. On average, the concentrations of acetic acid in the reactors were lowest in R4 and highest in R1, ranging between $1.75( \pm 0.430)$ and $2.31( \pm 0.120) \mathrm{g} \mathrm{L}^{-1}$ (Figure 1E). The average concentrations of propionic acid varied between $1.43( \pm 0.482)$ and $1.86( \pm 0.351) \mathrm{g} \mathrm{L}^{-1}$ (Figure 1F), with the highest levels in R1 and the lowest in R2.

High levels of acetate are common in stable biogas reactors, while propionic acid has been reported to inhibit methanogenic activity in the range $0.8 \mathrm{~g} \mathrm{~L}^{-1}$ [35] to $6 \mathrm{~g} \mathrm{~L}^{-1}$ [36]. Previous studies investigating methanogenic populations' adaptation capabilities to $\mathrm{NH}_{4}{ }^{+}, \mathrm{NH}_{3}$, and VFAs have shown that methane production can be maintained in environments with high concentrations of these compounds [29]. The concentrations of $\mathrm{NH}_{4}{ }^{+}$and VFAs observed in this study (Figure 1) were not alarmingly high, and the stable performance of the reactors suggest that the microbial communities in the reactors adapted to these conditions.

The amount of VS reduction (Figure 1B) supports the results of the other parameters measured, showing that the anaerobic degradation was somewhat lower in $\mathrm{R} 1$ than in the other reactors. The VS reduction in R1 decreased from 72.1 to $68.5 \%$ from the startup of the continuous process to day 59 , and the average VS reduction value in this reactor was $70.4( \pm 0.7) \%$ (Figure $1 B)$. In $R 2$, $\mathrm{R} 3$, and R4, the VS removal values were quite similar and stable, with average values of $71.8( \pm 0.4), 70.6( \pm 1.0)$, and $71.7( \pm 0.7) \%$, respectively.

\section{Sequencing, coverage, and taxonomic richness}

The results from pyrosequencing of the inoculum and the four reactors (day 59) before and after quality filtering are shown in Table 2. Unless otherwise specified, all percentages in the following text refer to the total number of reads in each of the filtered datasets.

Rarefaction analysis in the program MEGAN was used to characterize the richness of taxa in the five metagenomes at the genus level and at the fully resolved level, where all species and strains were included (Figure 2). At the genus level, the curves were leveling off, indicating acceptable sampling and coverage of the richness in the samples. We detected from 324 (R3) to 496 (R2) genera (given as number of leaves in Figure 2). At the fully resolved level the number of taxa was in the range of 519 (R3) to 906 (R2). The richness in the samples was approximately proportional to the number of reads in the datasets (Table 2), and this may explain some of the variation in the number of taxa detected in the different samples. The high taxonomic richness shows that the samples harbor complex prokaryotic communities. The taxonomic richness in the inoculum (IN) was in the range of the reactor samples (R1 to R4).

Effective genome size (EGS) is a computational method to predict the average genome size, including multiple plasmid copies, inserted sequences, and associated phages and viruses, from short sequencing reads of metagenomes. EGS has been suggested as a link between the genome size and the functional repertoire of the metagenome; the greater the functional complexity, the greater the EGS [37]. In addition to the EGS values (Table 3), we calculated the probability $(\mathrm{P})$ for detection of hits to a theoretical gene $(\mathrm{X})$ of 1,000 bp. The expected number of hits to this gene $\mathrm{X}$ was calculated, assuming one copy number of this gene was present in all organisms in our communities. In the reactor samples (R1 to R4) the average EGS was 2.5. The slightly greater EGS in the inoculum (IN) than in the reactor samples may therefore indicate greater functional complexity in the inoculum compared to the reactor samples, which have experienced selective pressure in the 59-day stabilization period.

\section{Taxonomic structure}

The taxonomy at the domain level in the reactor samples and in the inoculum is shown in Figure 3. 75.64 to $78.48 \%$ of the total reads were assigned to taxa in MEGAN, while 21.46 to $24.31 \%$ were assigned to no hits. From $69.33 \%$ to $71.84 \%$ of the total reads were Bacterial, while $0.71 \%$ to $1.25 \%$ were assigned to Archaea. Although Archaea is usually less abundant than Bacteria in biogas reactors [38], the reads assigned to Archaea in our reactors are in the lower range of earlier reports. Typically, Archaea in biogas

Table 2 Characteristics of metagenomic reads before and after quality filtering derived from DNA extracted from the four biogas reactors and their inoculum

\begin{tabular}{|c|c|c|c|c|c|}
\hline \multirow[t]{2}{*}{ Metagenome } & \multirow{2}{*}{$\begin{array}{l}\text { Raw dataset } \\
\text { Number of reads }\end{array}$} & \multicolumn{4}{|l|}{ Filtered dataset } \\
\hline & & Number of reads & Reads (\%) & Mean sequence length (bp) & Mean GC ratio (\%) \\
\hline $\mathrm{R} 1$ & 245499 & 177017 & 72.10 & 413 & 43.08 \\
\hline $\mathrm{R} 2$ & 548434 & 390641 & 71.23 & 417 & 42.86 \\
\hline R3 & 182122 & 130610 & 71.72 & 410 & 43.75 \\
\hline R4 & 286008 & 205035 & 71.72 & 413 & 43.65 \\
\hline IN & 241804 & 172150 & 71.19 & 409 & 43.10 \\
\hline
\end{tabular}




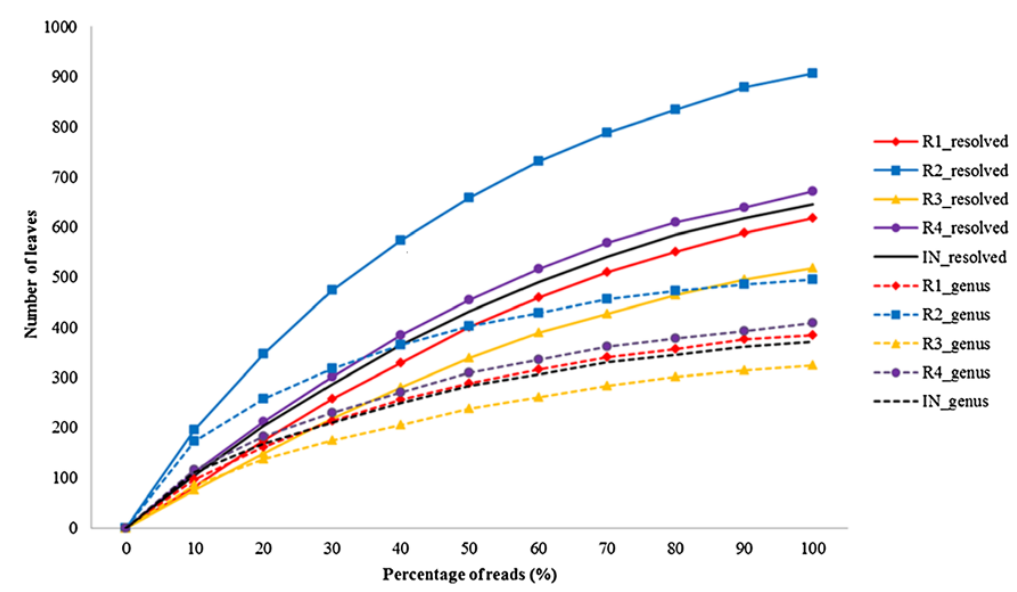

Figure 2 Rarefaction curves of taxonomic richness in the samples at the genus and the fully resolved level in MEGAN.

reactors is reported to be around $10 \%$ of the total reads [38-40]. However, other studies have reported Archaeal reads as low as $0.5 \%$ [41].

Eukaryota and viruses were also present in the metagenomes, representing from $0.44 \%$ to $0.58 \%$ and from $0.11 \%$ to $0.14 \%$, respectively. Sample IN differed from the reactor samples by slightly greater percentages of reads assigned to Bacteria, Archaea, Eukaryota, and viruses, resulting in a corresponding reduction in reads with no hits.

A comparison of the taxonomic structures in the samples of phyla with more than $0.1 \%$ of the total number of reads assigned, in at least one metagenome, are given in Figure 4. The most abundant phyla in all the reactor samples were Firmicutes followed by Bacteroidetes and Cloacimonetes (WWE1). Together these phyla represented about 40 to $50 \%$ of all reads. This is in agreement with other investigations, which report that in nearly all microbial populations in methane-producing reactors, species from Firmicutes and Bacteroidetes are dominant $[40,42]$. It is therefore likely that these phyla are ubiquitous in all biogas reactors.

The structure in the inoculum (IN) differed from that of the reactor samples (R1 to R4) in several ways. IN harbored more of Firmicutes, Proteobacteria, Euryarchaeota, Actinobacteria, and Synergistetes, compared to the reactor samples. Comparison of the reactor samples only showed

Table 3 Effective genome size of the metagenomes

\begin{tabular}{llll}
\hline Metagenome & $\begin{array}{l}\text { Effective genome } \\
\text { size (Mbp) }\end{array}$ & $\begin{array}{l}\text { Probability (P) } \\
\text { of hitting gene X }\end{array}$ & $\begin{array}{l}\text { Expected hits } \\
\text { to gene X }\end{array}$ \\
\hline R1 & 2.2 & 0.000452462 & 80.0934268 \\
R2 & 2.5 & 0.000404997 & 71.69129853 \\
R3 & 2.6 & 0.000377457 & 66.81634238 \\
R4 & 2.5 & 0.000394418 & 69.8187181 \\
IN & 3.2 & 0.000314795 & 55.72407323 \\
\hline
\end{tabular}

that R1 differed from the other samples. In particular, the abundance of Firmicutes is lower and the level of the in silico phylum, Cloacimonetes (WWE1), is greater in R1 than in the other reactor metagenomes. Proteobacteria, Euryarchaeota, Spirochaetes, and Tenericutes were also more abundant in R1 compared to the other reactors.

Due to the complexity of the metagenomes, a principal component analysis (PCA) plot, at the phylum level, was constructed to view the clustering of the five samples (Figure 5). The reactor samples R2, R3, and R4 were highly similar and clustered closely in the lower right quadrant, while sample R1, located in the upper left quadrant, differed in several ways from the other reactor metagenomes. As expected, the inoculum sample separated from all the reactor samples in the PCA plot and was positioned in the upper right quadrant. The abundances of Firmicutes and Cloacimonetes (WWE1) were the most important parameters for positioning of the samples along the first principal component (PC1). Firmicutes, Actinobacteria, and Synergistetes all had positive scores along $\mathrm{PC} 1$, indicating that the samples placed on the right section of the PCA plot (IN, R2,R3,R4) had relatively high abundances of these taxa compared to sample R1. Proteobacteria and Euryarchaeota have positive scores along $\mathrm{PC} 1$ but also strong positive scores at $\mathrm{PC} 2$, indicating a greater abundance of these phyla in R1 and IN compared to the other samples. The separation of R1 from the other reactor samples (R2, R3, and R4) is mainly due to its high content of Cloacimonetes (WWE1) but also of Bacteroidetes.

Of the 324 to 496 genera detected in the rarefaction analysis (Figure 2), 44 genera were characterized as highly abundant as each of them harbored $\geq 0.1 \%$ of the reads in one or more of the metagenomes (Figure 6). Candidatus Cloacimonas (of the phylum Cloacimonetes (WWE1)) [43] is the most abundant genus in the reactor samples, where it represented from $3.26 \%$ (R2) to $10.10 \%$ (R1) of the reads. 


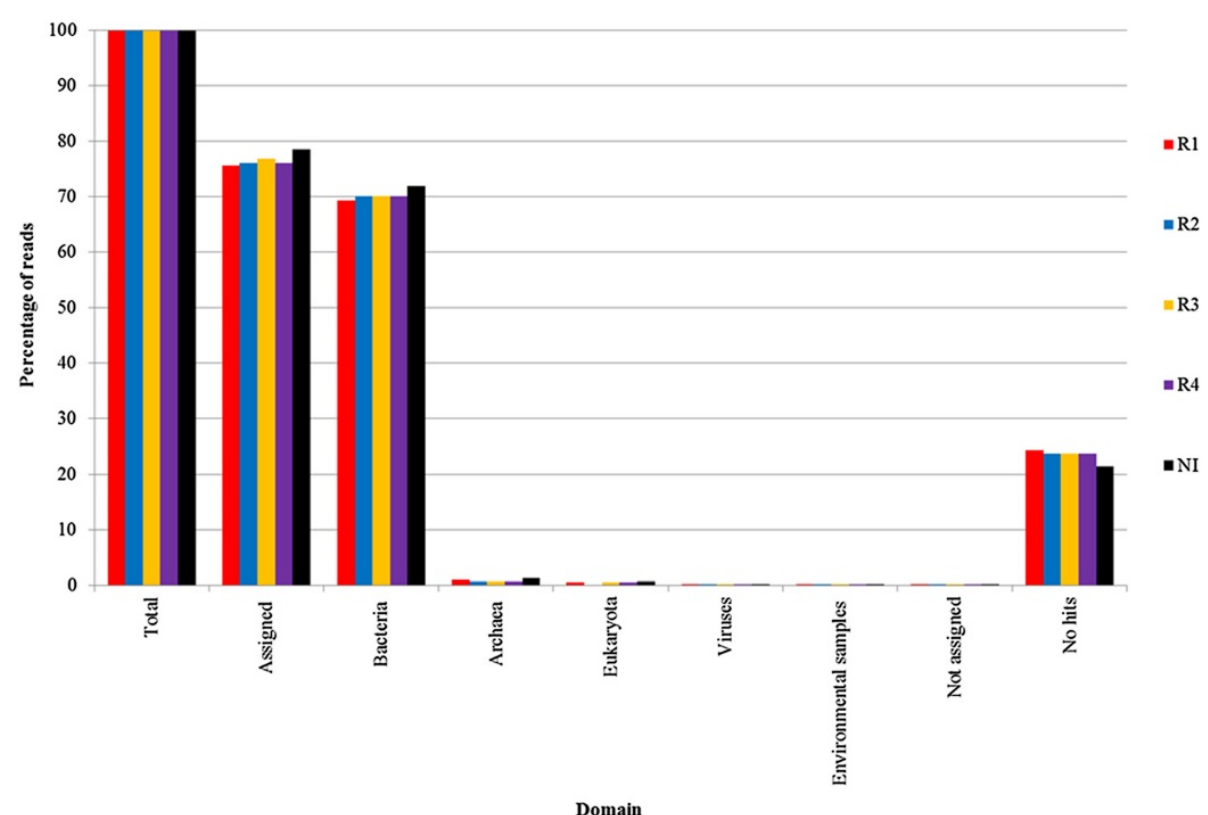

Figure 3 Taxonomic distribution at the domain level in MEGAN. Reads assigned at the domain level given as percentage of total reads in each metagenome. "No hits" are reads without hits in the BLAST search. "Not assigned" are reads with a hit in BLAST, but with no assignment to a taxon due to the settings in MEGAN. "Environmental samples" are reads with hits in other metagenome sequences with unknown biological classification.

The abundance of this taxon in the inoculum (IN) is considerably lower $(0.12 \%)$. An increasing abundance of phylum Cloacimonetes (WWE1) over longer anaerobic digestion periods has been observed previously [44]. The species Candidatus Cloacimonas acidaminovorans has not been cultivated, and the complete genome was reconstructed from a metagenomic analysis of a biogas reactor digesting municipal wastewater [45]. In silico proteome analysis indicated that this bacterium derived most of its carbon and energy from the fermentation of amino acids. The gene content suggests Candidatus Cloacimonas acidaminovorans to be a syntroph producing $\mathrm{H}_{2}$ and $\mathrm{CO}_{2}$ from formate, and this strain is probably present in many anaerobic digesters [45].



Figure 4 Percentage of reads assigned to prokaryotic phyla with more than $0.1 \%$ of total reads assigned. 


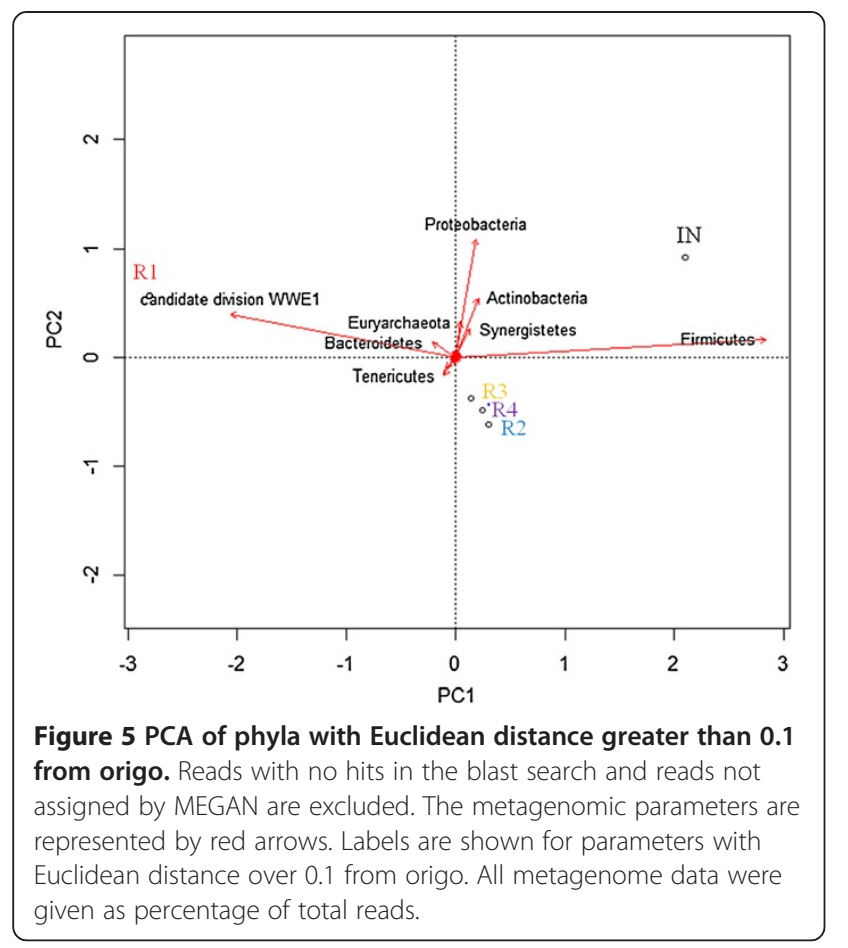

Altogether 25 genera of the phylum Firmicutes were among the highly abundant genera (Figure 6). The two genera, Clostridium and Syntrophomonas, each accounted for about 1 to $2 \%$ of the reads in all the five metagenomes. The 23 remaining highly abundant Firmicutes genera were: Alkaliphilus, Anaerococcus, Bacillus, Dethiobacter, Butyrivibrio, Desulfitobacterium, Desulfosporosinus, Desulfotomaculum, Eubacterium, Halothermothrix, Lactobacillus, Mahella, Moorella, Paenibacillus, Pelotomaculum, Peptoniphilus, Ruminococcus, Streptococcus, Syntrophothermus, Tepidanaerobacter, unclassified Clostridiales (miscellaneous), unclassified Erysipelotrichaceae, and unclassified Lachnospiraceae. The following six genera of the phylum Bacteroidetes were also among the highly abundant taxa (Figure 6): Alistipes, Bacteroides, Dysgonomonas, Odoribacter, Porphyromonas, and Prevotella. Three genera of the phylum Synergistetes (Anaerobaculum, Anaerophaga, Synergistes), three genera of the Archaeal phylum Euryarchaeota (Methanobrevibacter, Methanoculleus, Methanosarcina; all methane producers) and two genera of the phylum Spirochaetes (Treponema and Sphaerochaeta) were also highly abundant in the metagenomes. In addition, we detected the following genera as highly abundant (phylum indicated in brackets): Acholeplasma (Tenericutes), Corynebacterium (Actinobacteria), Haloplasma (unclassified Bacteria), and Pseudomonas (Proteobacteria).

The most abundant genus of Firmicutes in the biogas reactors was Clostridium. In general, Clostridia are known to be involved in the hydrolytic digestion of macromolecular compounds in the first step of a fermentation process, and therefore play a crucial role in biogas production $[38,46,47]$.

The taxonomic analysis revealed great diversity of highly abundant genera in all samples. Still the high

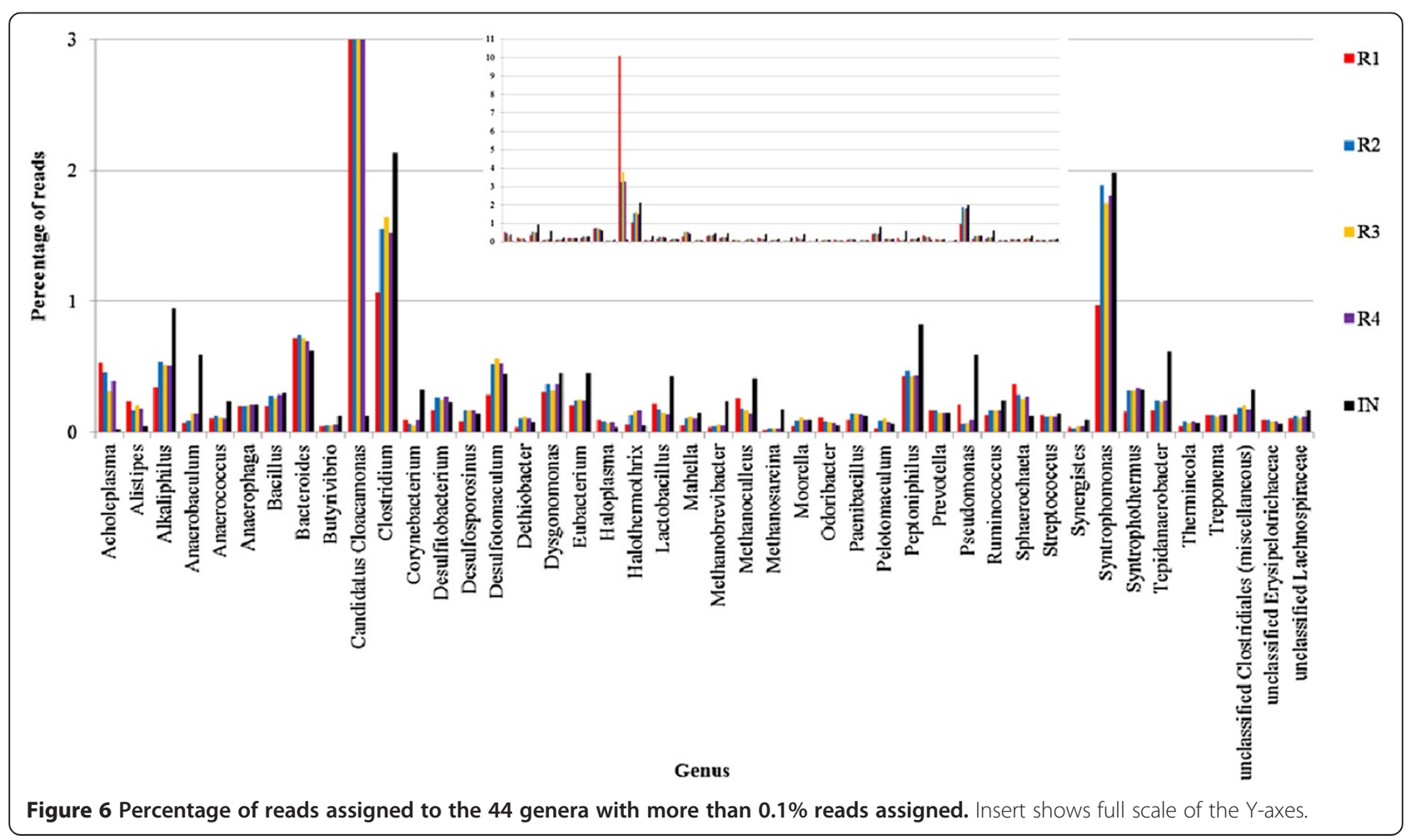


abundance of Candidatus Cloacimonas, Clostridium, and Syntrophomonas indicated a major role of these genera in the biogas reactors and in the inoculum. Abundance shifts in the reactor samples compared to the inoculum at the genus level are illustrated in Figure 7. The predominant change is the large increase of Candidatus Cloacimonas in the reactor samples, especially R1, indicating an important role of this genus in the reactors. There is also a relatively large increase in the abundance of Acholeplasma, while Pseudomonas, Anaerobaculum, Corynebacterium, Methanobrevibacter, and Methanosarcina are among the genera most reduced in their abundance compared to the inoculum.

To further study the clustering of the metagenomes, a PCA plot at the genus level was constructed. All genera were included, but reads with no hits were excluded (Figure 8). When the genus level was used, the metagenomes of R2, R3, and R4 clustered more closely than in the PCA plot at the phylum level (Figure 6). The overall clustering pattern of the samples at the genus level is however similar to the clustering detected at the phylum level. This supports consistency in the clustering analysis using PCA and shows that the same clustering is expressed at two quite different taxonomic levels of these complex metagenomes. Figure 8 shows that it is the significantly higher abundance of the genus Candidatus Cloacimonas in R1 that gives the major contribution to R1's separation from samples R2, R3, and R4. Inspection of the MEGAN charts showed that all reads of this genus were further assigned to the strain Candidatus Cloacimonas acidaminovorans str. Evry. As suggested from a reconstruction of the complete genome [45], this uncultivated strain is probably a syntrophic bacterium that is present in many anaerobic digesters.

In a previous study carried out by Kovács et al. [48], changes in the composition of the microbial community were detected through the use of a highly parallel SOLiD ${ }^{\circ}$ (Sequencing by Oligo Ligation and Detection) next generation DNA sequencing on samples from fed-batch reactors fed with a low $\mathrm{C} / \mathrm{N}$ ratio substrate. It was found that the bacterium Candidatus Cloacimonas acidaminovorans disappeared when the reactors were added a protein monosubstrate with a $\mathrm{C} / \mathrm{N}$ ratio of 3 . This bacterium is not capable of producing polyamines and a number of other cofactors. In our experiments we observed an increase in the abundance of Candidatus Cloacimonas acidaminovorans in all reactors (Figure 6).

The Firmicutes genus Syntrophomonas strongly influenced the clustering of R2, R3, and R4 in the lower right quadrant. It should be noted that the abundance of this genus is much less in R1 compared to the other reactors and the inoculum. Inspection of the MEGAN charts revealed the strain Syntrophomonas wolfei as the predominant Syntrophomonas in all the five metagenomes.

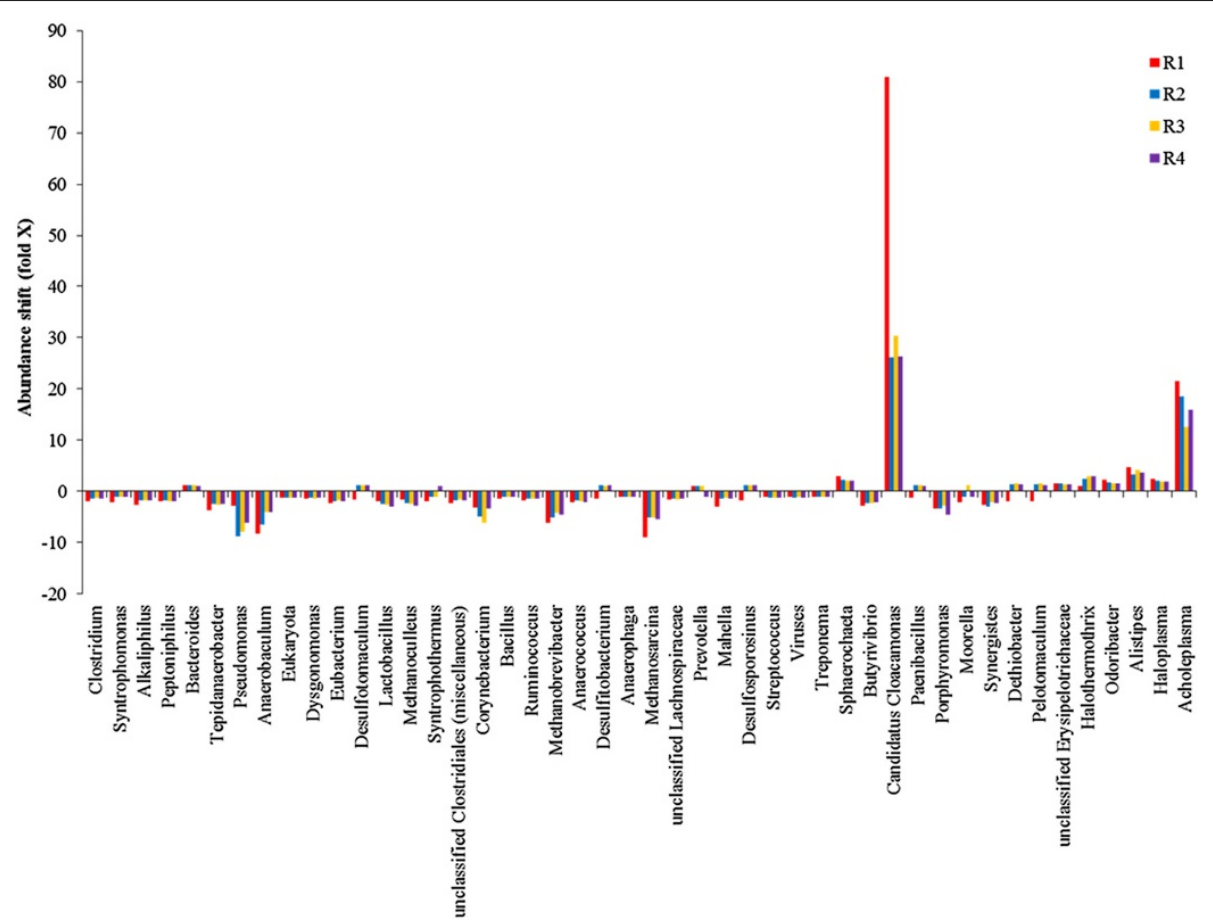

Figure 7 Abundance shift compared to inoculum at the genus level. This figure shows the fold change in abundant genera $(>0.1 \%$ in one or more metagenomes) in the reactor samples compared to the inoculum. Fold change values less than 1 were replaced by the negative of their inverse. 


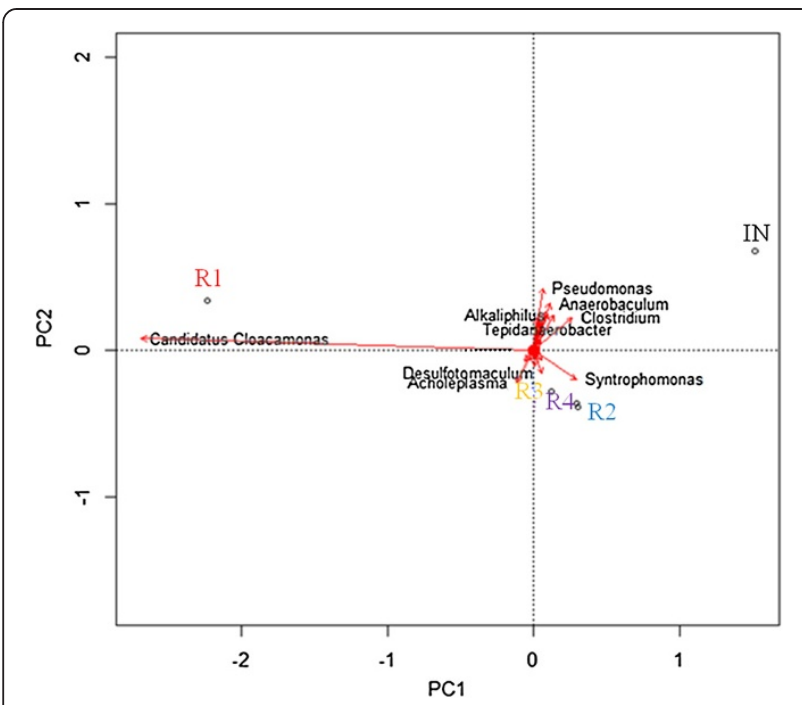

Figure 8 PCA of genera with Euclidean distance from origo greater than 0.1. Reads with no hits in the BLAST search and reads not assigned by MEGAN are excluded. The metagenomic parameters are represented by red arrows. Labels are shown for parameters with Euclidean distance over 0.1 from origo. All metagenome data were given as percentage of total reads.

S. wolfei is a Gram-negative bacterium isolated from anaerobic environments like aquatic sediments or sewage sludge [49]. This organism is able to beta-oxidize saturated fatty acids ( $\mathrm{C} 4$ to $\mathrm{C} 8$ fatty acids) anaerobically to acetate, or to acetate and propionate, in the presence of a syntrophic partner [50]. Fatty acid degradation also leads to production of $\mathrm{H}_{2}$, which is consumed by a syntrophic methanogenic partner (the Methanomicrobiales strain Methanospirillum hungatei has been reported) [51]. The syntrophic $\mathrm{H}_{2}$ transfer mechanism from Syntrophomonas to the methanogen is probably mediated by format because $\mathrm{H}_{2}$ cannot diffuse rapidly enough to account for the level of methane synthesis in methanogenic cultures [52]. Another synergist known to be involved in syntrophic acetate oxidation under high $\mathrm{NH}_{4}{ }^{+}$ concentrations, Tepidanaerobacter acetatoxydans [10,11], was detected in our biogas reactors, with higher abundance in R2, R3, and R4 than in R1. Potential methanogenic syntrophic partners to Syntrophomonas were also present in the metagenomes. The methanogenic genus Methanospirillum was present with low density in all the reactor samples in this study (data not shown), but the genera Methanoculleus and Methanobrevibacter (Figure 6) were abundant. Overall, the high abundance of syntrophic Bacteria indicates that syntrophic methane production is important in these reactors.

\section{Methanogenesis and subsystems of metabolism}

The methanogenic Archaea play a major role in the global carbon cycle by carrying out the final methane-producing step in the anaerobic degradation of organic materials. Methanogens typically thrive in environments where all electron acceptors other than $\mathrm{CO}_{2}$ are depleted.

Inspection of the MEGAN charts of Euryarchaeota at the genus level revealed great diversity in all metagenomes. The genus Methanoculleus of the order Methanomicrobiales, followed by the genus Methanobrevibacter of the order Methanobacteriales (both orders are known to produce methane from $\mathrm{H}_{2}$ and $\mathrm{CO}_{2}$ ) were the most abundant in all the samples (Table 4). Methanosarcina and Methanosaeta of the order Methanosarcinales were present, but the abundance was significantly lower. Members of the genus Methanoculleus are among the most prevalent methanogens found in wastewater, sewage bioreactors, and landfills [53]. All reads of the genus Methanoculleus in the MEGAN analyses were further assigned to the species Methanoculleus marisnigri JR1. This organism has all genes required for methanogenesis from hydrogen and $\mathrm{CO}_{2}$ [54]. In addition this organism can use formate and secondary alcohols such as propanol and butanol as electron donors in methanogenesis. The high abundance of Methanomicrobiales in the reactor samples is in consistence with the relative high VFA levels in the reactors, which indicate high hydrogen production. The high levels of acetate in the reactors are in accordance with the abundance of the methanogenic genus Methanosarcina (M. acetivorans, M. barkeri, and M. mazei). These methanogens are known to be capable of using all the three degradation pathways for methane formation (acetate, methyl, and hydrogen). Acetate cleavage has been regarded to be dominated by Methanosarcinaceae at high acetate concentrations and by Methanosaetaceae at low acetate concentrations [55]. Absence of Methanosaetaceae is also correlated with acetate oxidation [55].

The abundance of Methanoculleus, Methanobrevibactor, Methanosarcina, and Methanosaeta in the reactor samples indicates that the methane production was carried out by both hydrogenotrophic and acetoclastic methanogenesis. Figure 9 shows the results from a KEGG analysis of functional enzymes involved in methane production. Enzymes for methane formation from both $\mathrm{CO}_{2}$ and hydrogen, and acetate were present in the reactors. These results support the assumption that methane was formed from both hydrogenotrophic and acetoclastic reaction pathways in the reactors.

Figure 10 shows the results from the KEGG analysis of metabolic systems that are related to methane production, including metabolism of amino acids, energy, carbohydrates, nucleotides, lipids, cofactors, vitamins, polyketides, terpenoids, glycan, and xenobiotics. These metabolic activities are associated with the conversion of biomass into methane during anaerobic fermentation. The results show that a large amount of reads are distributed among amino acid metabolism and carbohydrate metabolism. 
Table 4 Percentage of reads assigned to the most abundant methanogenic genera

\begin{tabular}{lllll}
\hline Metagenome & Methanoculleus & Methanobrevibacter & Methanosarcina & Methanosaeta \\
\hline R1 & 0.264 & 0.038 & 0.019 & 0.021 \\
R2 & 0.183 & 0.046 & 0.034 & 0.017 \\
R3 & 0.164 & 0.057 & 0.034 & 0.011 \\
R4 & 0.145 & 0.052 & 0.031 & 0.018 \\
IN & 0.417 & 0.236 & 0.171 & 0.017 \\
\hline
\end{tabular}

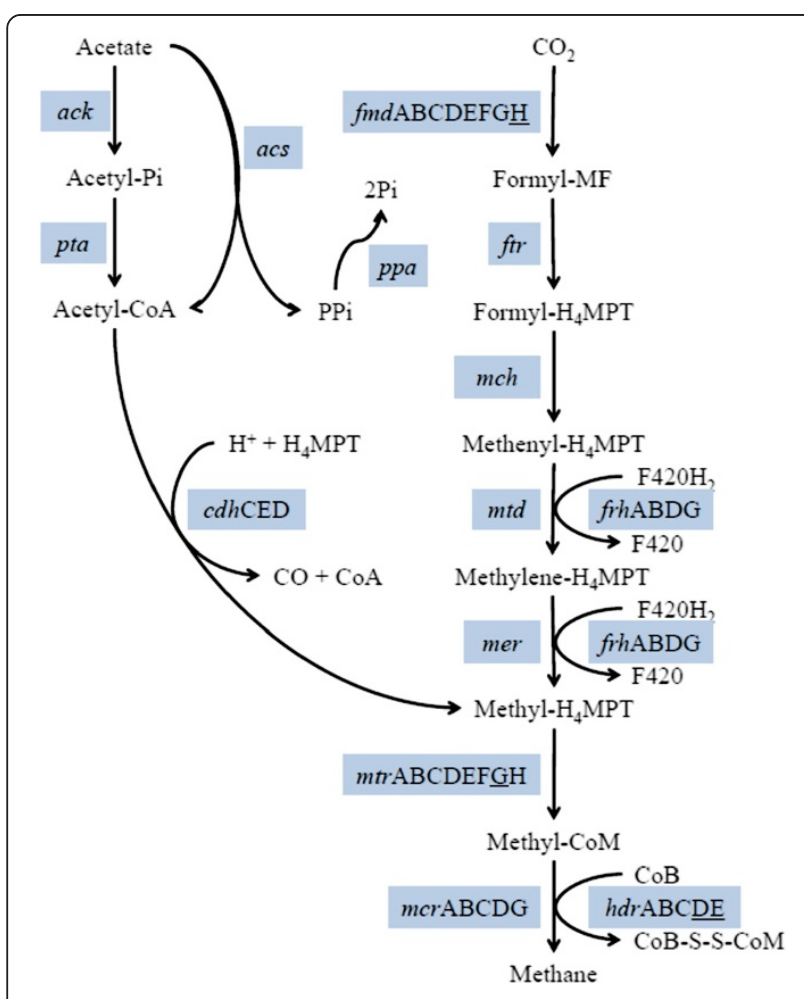

Figure 9 The methanogenesis pathway. Enzymes are shown in blue boxes. Subunits missing in all our datasets (R1, R2, R3, R4, and IN) after search against the KO database at MG-RASTare underlined. Abbreviations used in the figure are Acetyl-Pi: acetyl phosphate; ack: acetate kinase; acs: acetyl-CoA synthetase; cdh: acetyl-CoA decarbonylase/synthase; CO: carbon monoxide; CoA: coenzyme A; CoB: coenzyme B; CoB-S-S-CoM: coenzyme M 7-mercaptoheptanoylthreonine-phosphate heterodisulfide; F420: coenzyme F420; fmd: formylmethanofuran dehydrogenase; Formyl-H4MPT: 5-formyl-5,6,7,8-tetrahydromethanopterin; Formyl-MF: $f$ ormylmethanofuran; frh: coenzyme F420 hydrogenase; ftr: formylmethanofuran-tetrahydromethanopterin $\mathrm{N}$-formyltransferase; H4MPT: 5,6,7,8-tetrahydromethanopterin; hdr: heterodisulfide reductase; mch: methenyltetrahydromethanopterin cyclohydrolase; mcr: methyl-coenzyme $M$ reductase; mer: 5,10-methylenetetrahydromethanopterin reductase; Methenyl-H4MPT: 5,10-methenyl5,6,7,8-tetrahydromethanopterin; Methyl-CoM: methylcoenzyme M; Methylene-H4MPT: 5,10-methylenetetrahydromethanopterin; Methyl-H4MPT: 5-methyl-5,6,7,8-tetrahydromethanopterin; mtd: methylenetetrahydromethanopterin dehydrogenase; $\mathrm{mtr}$ : tetrahydromethanopterin S-methyltransferase; ppa: inorganic diphosphatase; pta: phosphate acetyltransferase.
This observation is consistent with the finding that many species found in the samples are involved in amino acid and carbohydrate digestion. The amount of protein in the fish waste silage that was added to our reactors during the experiment is $15 \%$ (ww), and the high content of protein in the substrate is consistent with the abundant reads for enzymes involved in the amino acid metabolism. In a previous study, Li et al. [41] used fatand protein-rich food waste as a biogas substrate, and they found that a significant amount of reads were obtained for the processes involved in the protein degradation pathway. Among the genes involved in the carbohydrate metabolism, those that degrade cellulose are particularly important for the efficient breakdown of substrates such as co-manure. The high percentage of reads assigned to carbohydrate metabolism and the abundance of the Firmicutes phylum and Clostridium genus in our reactors demonstrate the importance of carbohydrate and cellulose degradation by the anaerobic microbial community.

The result on carbohydrate metabolism is in agreement with previous investigations $[47,56,57]$, and the evaluation of metabolic pathways shows that the capabilities of metabolism varied somewhat in the different reactors. Enzymes related to metabolism of amino acids and cofactors and vitamins were highest in the IN sample. Among the reactor samples, R1 in general had the fewest reads assigned to metabolic subsystems, while the highest number of reads assigned to subsystems was detected in R2 and $\mathrm{R} 4$.

Methane production in R1 was somewhat lower than in the other reactors. The propionic acid concentration in this reactor was somewhat higher than in the other reactors. This, together with the high abundance of Candidatus Cloacimonas acidaminovorans in R1 may have had an impact on this reactor's somewhat lower metabolic capabilities. The high prevalence of the bacterium might have been an inhibiting factor in R1.

\section{Conclusions}

Taxonomic and functional studies of inoculum and reactor samples showed that the microbial consortium changed over time in the four reactors during the digestion phase. The results show that the microbial community in the four biogas reactors after 59 days of operation was different 


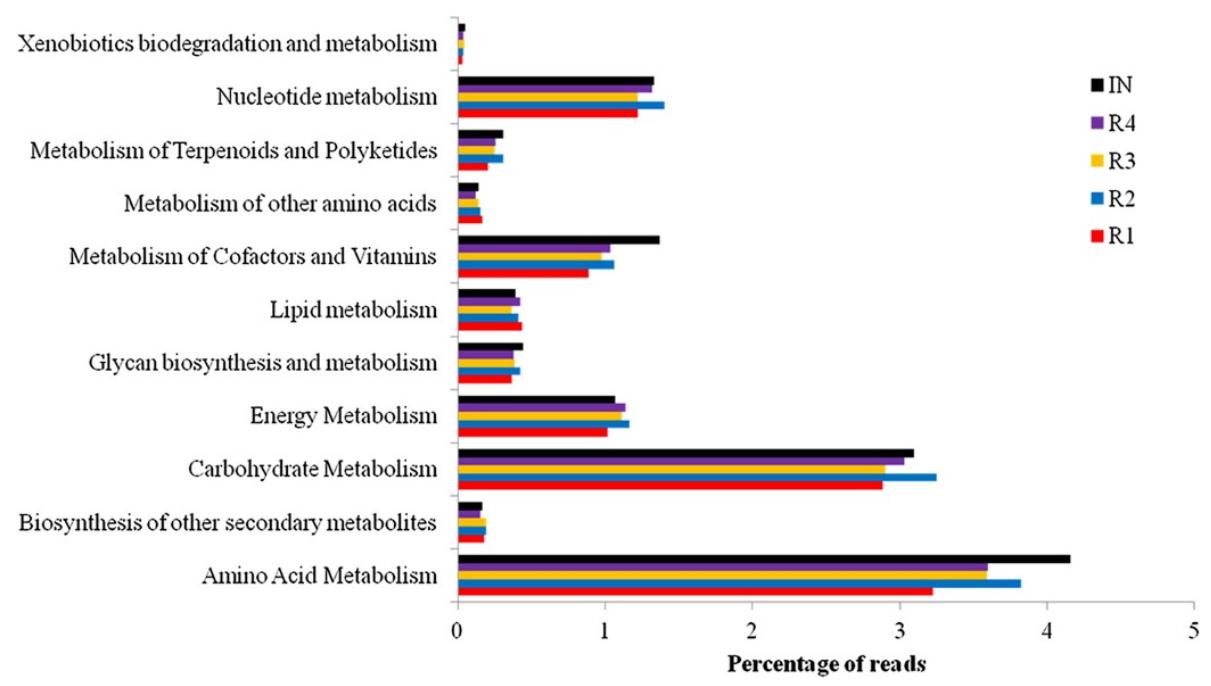

Figure 10 Reads assigned to level 2 metabolism subsystems at MG-RAST (KO database).

from the microbial composition in the inoculum. A greater functional complexity was detected in the inoculum compared to the reactor samples. Microbial communities tend to become more specific and less complex over time when degrading the same substrate. The results showed that the microbial composition developed quite similarly in three of the four parallel reactors during the experiment.

Bacteria from the phylum Firmicutes were most abundant in the reactors, followed by the phyla Bacteroidetes and Proteobacteria. In particular, the species from genera Clostridium and Syntrophomonas play key roles in the initial degradation of protein, cellulose, and other polysaccharides. These results were further supported by gene functional annotation, where we detected many enzymes involved in protein degradation and carbohydrate metabolism. The dominant methanogens present in the reactors were from Methanomicrobiales, and the most prevalent genus appeared to be Methanoculleus. Methanobrevibacter, Methanosarcina, and Methanosaeta were also detected in the samples. These methanogens use versatile substrates and contain both acetotrophic and hydrogenotrophic pathways for methane production.

The microbial composition in one reactor (R1) differed from those of the others, especially in relation to the high prevalence of the Bacterium Candidatus Cloacimonas acidaminovorans. This reactor also showed lower average methane production and VS removal than the other three reactors, and this might be linked to the difference in microbiology. One possible theory for the dissimilarity is that the high density of the Candidatus Cloacimonas acidaminovorans in $\mathrm{R} 1$ may have had a negative impact on the syntrophic relationships between Bacteria and methanogens in this reactor. $\mathrm{R} 1 \mathrm{had}$, in addition to very high values of Cloacimonetes (WWE1), also a low density of Firmicutes, a phylum consisting of many important syntrophic members of the class Clostridia (e.g. Syntrophomonas). The reactor also had a low density of the syntrophic acetate-oxidizing bacteria Tepidanaerobacter acetatoxydans. It should be noted that the 454 sequencing in this study was not done in replicate, mainly due to the cost of the analysis. While the method is known to be very reproducible [58], future studies of parallel reactors should ideally also include replicate sequencing.

This study showed that four parallel reactors codigesting manure and fish waste silage operated stably during a startup phase. Clear changes in the microbial population were seen in all four reactors, the most pronounced being the increased abundance of Candidatus Cloacimonas acidaminovorans. Additionally, several important Archaea and Bacteria degrading the protein-rich substrate were identified. In particular, microorganisms involved in syntrophic methane production seemed to be important. These results give leads for the design of well-functioning microbial communities for biogas plants digesting similar substrates.

\section{Materials and methods}

\section{Inoculum, substrate, and reactors operation}

Slurry from a biogas reactor co-digesting a mix of $19 \%$ $(\mathrm{v} / \mathrm{v})$ fish waste silage and $81 \%$ cow manure [1] was used as the inoculum (IN). In a previous study the high amount of amount of fish waste silage led to process inhibition due to overloading of protein and fat. The slurry from this reactor was kept without any addition of substrate for 50 days, until startup of the present experiment. The chemical composition of the inoculum was measured in triplicate samples, and had the following characteristics: $\mathrm{pH}=8.1( \pm 0.09)$, $\mathrm{NH}_{4}{ }^{+}\left(\mathrm{g} \mathrm{L}^{-1}\right)=5.5( \pm 0.08), \mathrm{DM}(\%)=6.3( \pm 0.06)$, VS of DM (\%) $=73.6( \pm 0.51)$. The substrate used was a mix of $87 \%$ cow manure and $13 \%$ fish waste silage $(\mathrm{v} / \mathrm{v})$. The substrate 
chemical composition was measured in triplicate samples, and its characteristics are shown in Table 1.

To four 10-L continuously stirred tank reactors, designated R1, R2, R3, and R4, were added $2.55 \mathrm{~L}$ inoculum (day 0 ). From day one substrate was added to the reactors every day until the effective reactor volume was $8 \mathrm{~L}$. The amount of substrate added each day was calculated from the reactors' increasing effective volume and 30 days HRT (for example, based on a reactor with $2.55 \mathrm{~L}$ effective volume and an HRT of 30 days: $2.55 \mathrm{~L} / 30 \mathrm{~d}=85 \mathrm{~mL}$ substrate/reactor/day). At day 36 the reactors were fed with $266.7 \mathrm{~mL}$ substrate, yielding a final effective volume of $8 \mathrm{~L}$. From day 36 to day 59 (28 days), the reactors were fed at a fixed rate of $266.7 \mathrm{~mL}$ substrate/reactor/day (this was based on reactors with $8 \mathrm{~L}$ effective volume, and an HRT of 30 days: $8 \mathrm{~L} / 30 \mathrm{~d}=266.7 \mathrm{~mL}$ substrate/reactor/day). The same amount of reactor slurry was removed (prior to substrate addition) each day to maintain the volume at $8 \mathrm{~L}$. The reactors were operated anaerobically at $37^{\circ} \mathrm{C}$ with a stirring speed of $150 \mathrm{rpm}$. The total carbon and nitrogen in the substrate was determined in single samples, and the carbon:nitrogen $(\mathrm{C} / \mathrm{N})$ ratio was calculated. Approximately $20 \mathrm{~g}$ inoculum was collected at day 0 , and $50 \mathrm{~g}$ slurry from each of the four reactors (R1, R2, R3, and R4) were collected at day 59 , and stored frozen $\left(-20^{\circ} \mathrm{C}\right)$ in $50 \mathrm{~mL}$ Nunc centrifuge tubes prior to DNA extraction.

\section{Chemical analysis procedures}

The content of DM and VS, and the pH in the inoculum, the reactor slurries, and in the substrate were determined according to standardized methods [59-61] every fourth day, in triplicate samples.

The $\mathrm{NH}_{4}^{+}$and VFA concentrations in the inoculum and in the reactor slurries were determined every fourth day. The concentration of $\mathrm{NH}_{4}^{+}$was determined in triplicate samples by use of an ammonium selective electrode (Thermo Scientific Orion ISE/NH4). Samples for $\mathrm{NH}_{4}{ }^{+}$ analysis were diluted (1:10) in distilled water and measured at $20^{\circ} \mathrm{C}$ and supplemented with an ionic strength adjustor (28.7 g glacial acetic acid $\mathrm{L}^{-1}$ and $53.6 \mathrm{~g}$ magnesium acetate $\left.\mathrm{L}^{-1}\right)$, using $10 \mathrm{~mL}$ of ionic strength adjustor per $100 \mathrm{~mL}$ of sample, for stabilization of $\mathrm{NH}_{4}{ }^{+}$. The $\mathrm{NH}_{3}$ concentrations were calculated based on the $\mathrm{NH}_{4}{ }^{+}$ concentrations. The average deviations between the triplicate samples (not shown) were $<0.5$. Samples for VFA (acetic acid and propionic acid) analysis were centrifuged $(13,000 \mathrm{rpm})$ and filtrated $(0.45 \mu \mathrm{m})$ prior to analysis. The concentrations of VFAs were determined in single samples, by use of a Rezex RFQ Fast Acid H + (8\%) $100 \times$ $7.8 \mathrm{~mm}$ HPLC (Phenomenex, Torrance, CA, USA), operated at a temperature of $85^{\circ} \mathrm{C}$, with an Ultimate 3000RS column and UV detection at $210 \mathrm{~nm}$ (Dionex, Sunnyvale, CA, USA ). The samples were diluted with sulfuric acid ( $8 \mu \mathrm{L}$ total) before analysis.
The elemental composition of carbon, hydrogen, and nitrogen was determined in the reactors' substrate by combustion using a LECO CHN-1000 instrument (St. Joseph, MI, USA).

The biogas was collected in 25-L Tedlar bags (Tedlar ${ }^{\circ}$ Gas Sampling Bag, Sigma-Aldrich, St. Louis, MO, USA). $\mathrm{CH}_{4}$ and $\mathrm{CO}_{2}$, as a percentage of the gas volume of samples, were measured once a day with a GA2000 Landfill Gas Analyzer (Geotechnical Instruments Ltd., UK). The total gas production rate volume $(\mathrm{L} / \mathrm{d})$ was calculated from flow measurements (rate $300 \mathrm{~cm}^{3} / \mathrm{min}$ ) as follows: (pump-number/60 seconds * $\left.300 \mathrm{~cm}^{3}-\mathrm{min}\right) /(1000 \mathrm{~mL})$.

\section{DNA extraction from reactor samples}

All samples for DNA extraction were collected at the same time and treated in exactly the same way. In order to achieve homogeneous and representative samples, the inoculum and the reactor slurries were thoroughly stirred before and during sampling. The samples were collected in 100-mL plastic bottles and frozen. The frozen samples of the inoculum (IN) and reactors (R1 to R4) were slowly thawed before the total genomic DNA was extracted from duplicate subsamples using a FastDNA SPIN Kit for soil (MP Biomedicals, Santa Ana, CA), according to the producer's instruction. Lysis and homogenization of the samples were performed in a Bertin Technologies (Rockville, MD) Precellys 24 system, for $2 \times 20$ seconds at speed 5400. Each subsample was eluted from the columns with $100 \mu \mathrm{L}$ DNase/pyrogen-free water (DES). The combined eluates were purified using a Wizard ${ }^{\bullet}$ DNA Clean-Up System (Promega, Madison, WI) and finally eluted from the Wizard column with $50 \mu \mathrm{l}$ DES. The DNA purity and concentrations were measured in a NanoVue spectrophotometer and Qubit assay using the Qubit ${ }^{\circ}$ 2.0 Fluorometer. The DNA quality and chain length were inspected in 1.2\% agarose (Biozyme RESult, LE General Purpose Agarose) gel in $1 \times$ Tris-acetate-EDTA with added $20 \mu \mathrm{L}$ SYBR Safe DNA gel stain, 10,000 concentration in DMSO (Life Technologies, Grand Island, NY) to a final gel volume of $200 \mathrm{~mL}$. DNA extracts were added using TrackIt ${ }^{\mathrm{mu}}$ Cyan/ Yellow Loading buffer (Invitrogen) to a final volume of $10 \mu \mathrm{L}$. Three microliters of Trackit ${ }^{\text {tat }} 100 \mathrm{bp}$ DNA Ladder (Invitrogen) were used. The agarose gel was run at $100 \mathrm{~V}$ for 90 minutes. Images of the gel were made using a KODAK Gel Logic 212 Imaging System for inspection of the chain length prior to 454 pyrosequencing.

\section{4 pyrosequencing}

Sample preparation and sequencing of extracted DNA were performed at the High Throughput Sequencing Centre at CEES, University of Oslo [62], according to standard 454 GS FLX Titanium protocol. The five samples were tagged, mixed, and sequenced on a $70 \times 75$ format PicoTiterPlate $^{\text {tx }}$ on a GS FLX Titanium instrument. The 
sequence data have been submitted to the NCBI database (http://www.ncbi.nlm.nih.gov) under BioProject accession number PRJNA261310.

\section{Quality filtering}

The complete datasets were analyzed with PRINSEQ [63] to determine the sequence quality scores. For each sample we performed quality filtering to remove low quality reads (reads containing $\geq 10$ ambiguous bp, homopolymers of $\geq 10 \mathrm{bp}$, and sequence length $<100 \mathrm{bp}$ ) in mothur v.1.25.1 [64]. The trimmed files were checked for artificial replicates using cdhit-454 with standard settings [65]. The cleaned files were analyzed with PRINSEQ before the files were uploaded at the Bioportal computer service [66] for Blast X against the NCBI nonredundant Protein database (ncbiP-nr). The maximum expectation value was set to $10^{-3}$, and a maximum of 25 alignments were reported per hit.

\section{Effective genome size}

The effective genome size (EGS) for each metagenome was estimated according to the method developed by Raes et al. [37], using the constants $\mathrm{a}=18.26, \mathrm{~b}=3650$, and $c=0.733$. A protein reference database containing the 35 single copy COGs in question was downloaded from STRING (v. 9.0) [67]. BlastX was conducted at the freely available Bioportal computer service [68]. The sampling probability of a random universal single copy gene (1000 bases) and expected number of reads detected were calculated according to Beszteri et al. [69].

\section{Taxonomic classification}

The BlastX output files were analyzed according to NCBI taxonomy in the program MEGAN, version $4[70,71]$ with default LCA parameters (Min Score: 35, Top Percent: 10.0, and Min Support: 5). All taxa were enabled.

\section{Principal component analysis}

The PCA plots were created using the vegan library in R [72] as previously described [73]. The ordination was based on reads assigned to the phylum and to the genus level in MEGAN. All metagenome data were given as a percentage of total reads.

\section{Metabolic annotation}

The metagenomic reads were assigned to subsystems on the MG-RAST server [74] (version 3.3.9) [75]. The KEGG Orthology (KO) reference database was used. The maximum expectation value was set to $10^{-5}$, the minimum alignment length was set to 50 bases, and the minimum percentage identity was set to $50 \%$. We used the same settings to search the metagenomes for key genes involved in methanogenesis.

\section{Abbreviations}

Acetyl-Pi: acetyl phosphate; ack: acetate kinase; acs: acetyl-CoA synthetase; cdh: acetyl-CoA decarbonylase/synthase; CO: carbon monoxide; CoA: coenzyme A; CoB: coenzyme B; CoB-S-S-CoM: coenzyme M 7-mercaptoheptanoylthreonine-phosphate heterodisulfide; DES: DNase/ pyrogen-free water; DM: dry matter; DMSO: dimethyl sulfoxide; F420: coenzyme F420; fmd: formylmethanofuran dehydrogenase; Formyl-H4MPT: 5-formyl-5,6,7,8-tetrahydromethanopterin; FormylMF: formylmethanofuran; frh: coenzyme F420 hydrogenase; ftr: formylmethanofuran-tetrahydromethanopterin N-formyltransferase; H4MPT: 5,6,7,8-tetrahydromethanopterin; hdr: heterodisulfide reductase; mch: methenyltetrahydromethanopterin cyclohydrolase; mcr: methylcoenzyme $M$ reductase; mer: 5,10-methylenetetrahydromethanopterin reductase; Methenyl-H4MPT: 5,10-methenyl-5,6,7,8-tetrahydromethanopterin; Methyl-CoM: methylcoenzyme M; Methylene-H4MPT: 5,10-

methylenetetrahydromethanopterin; Methyl-H4MPT: 5-methyl-5,6,7,8tetrahydromethanopterin; mtd: methylenetetrahydromethanopterin dehydrogenase; mtr: tetrahydromethanopterin S-methyltransferase; ppa: inorganic diphosphatase; pta: phosphate acetyltransferase; VFA: volatile fatty acid; VS: volatile solids.

\section{Competing interests}

The authors declare that they have no competing interests.

\section{Authors' contributions}

SJH and AGR conceptualized the work and wrote parts of the manuscript. LS did all the experimental work with the biogas reactors and wrote most of the manuscript. AGR planned and carried out the DNA extraction and metagenome analysis. OEH contributed to the metagenome analysis and made several of the figures. All authors read and approved the final manuscript.

\section{Acknowledgement}

This work was supported by the Norwegian Research Council under project numbers 203402, 208019, 228747 and 193817. The authors wish to acknowledge the financial support of the Norwegian Agricultural Authority. The study was carried out under CenBio, a Norwegian Centre for Environmentally Friendly Energy Research. Additional financial support was provided by Follo Ren IKS and Lindum AS.

\section{Author details}

${ }^{1}$ Bioforsk, Norwegian Institute for Agricultural and Environmental Research, Frederik A. Dahls vei 20, 1432 Ås, Norway. ${ }^{2}$ Department of Microbiology, Oslo University Hospital, P.O. Box 4950, Nydalen, 0424 Oslo, Norway. ${ }^{3}$ Department of Chemistry, Biotechnology and Food Science, Norwegian University of Life Sciences, P.O. Box 5003, N-1432, Ås, Norway. "Norwegian Geotechnical Institute, Sognsveien 72, P.O. Box 3930, Ullevål Stadion, N-0806 Oslo, Norway.

Received: 13 June 2014 Accepted: 22 September 2014

Published online: 14 October 2014

\section{References}

1. Solli L, Bergersen O, Sørheim R, Briseid T: Effects of a gradually increased load of fish waste silage in co-digestion with cow manure on methane production. Waste Manage 2014, 34:1553-1559.

2. Statistics Norway. SSB. 2013.Avfallsregnskapet 2011. http://www.ssb.no/ natur-og-miljo/statistikker/avfregno.

3. Daniel SL, Drake HL: Oxalate- and glyoxylate-dependent growth and acetogenesis by Clostridium thermoaceticum. App/ Environ Microbiol 1993, 59:3062-3069.

4. Anderson I, Ulrich LE, Lupa B, Susanti D, Porat I, Hooper SD, Lykidis A, Sieprawska-Lupa M, Dharmarajan L, Goltsman E, Lapidus A, Saunders E, Han C, Land M, Lucas S, Mukhopadhyay B, Whitman WB, Woese C, Bristow J, Kyrpides N: Genomic characterization of methanomicrobiales reveals three classes of methanogens. PLoS One 2009, 4:6.

5. Zinder SH: Physiological ecology of methanogenesis. In Methanogenesis. Ecology, Physiology, Biochemistry and Genetics. Volume 1. 1st edition. Edited by Ferry JG. New York: Chapman and Hall; 1993:128-206.

6. Garcia JL, Patel BKC, Ollivier B: Taxonomic, phylogenetic and ecological diversity of methanogenic Archaea. Anaerobe 2000, 6:105-226. 
7. Liu Y, Whitman WB: Metabolic, phylogenetic, and eclogical diversity of the methanogenic Archaea. Annu N Y Acad Sci 2008, 1125:171-189.

8. Schnurer A, Zellner G, Svensson BH: Mesophilic syntrophic acetate oxidation during methane formation in biogas reactors. FEMS Microbiol Ecol 1999, 29:249-261.

9. Schnurer A, Nordberg $\AA$ : Ammonia, a selective agent for methane production by syntrophic acetate oxidation at mesophilic temperature. Water Sci Technol 2008, 57:735-740.

10. Westerholm M, Dolfing J, Sherry A, Grey ND, Head IM, Schnurer A: Quantification of syntrophic acetate oxidizing microbial communities in biogas process. Environ Microbiol Reports 2011, 3:500-505.

11. Westerholm M, Muller B, Arthurson V, Schnurer A: Changes in the acetogenic population in a mesophilic anaerobic digester in response to increasing ammonia concentration.J. Microbes Environ 2011, 26:347-353.

12. Chen Y, Cheng JJ, Creamer KS: Inhibition of anaerobic digestion process: a review. Bioresource Technol 2008, 99:4044-4064.

13. Pandey PK, Ndegwa PM, Soupir ML, Alldrege RJ, Pitts MJ: Efficacies of inocula on the startup of anaerobic reactors treating dairy manure under stirred and unstirred conditions. Biomass Bioenerg 2011, 35:2705-2720.

14. Demirel B, Yenigun O: Two-phase anaerobic digestion process: a review. J Chem Technol Biotechnol 2002, 77:743-755.

15. Weiland P: Biogas production: current state and perspectives. Appl Microbiol Biot 2010, 85:849-860.

16. Harmsen HJN, Kengen HMP, Akkermans ADL: Detection and localization of syntrophic propionate-oxidizing bacteria in granular sludge by in situ hybridization using $16 \mathrm{~s}$ rRNA-based oligonucleotide probes. App/ Environ Microbiol 1996, 62:1656-1663.

17. Amani T, Nosrati M, Mousavi SM, Kermanshahi RK: Analysis of the syntrophic anaerobic digestion of volatile fatty acids using enriched cultures in a fixed-bed reactor. Water Environ Res 2012, 84:460-472

18. Nielsen HB, Angelidaki I: Strategies for optimizing recovery of the biogas process following ammonia inhibition. Bioresource Technol 2007, 99:7995-8001.

19. Angelidaki I, Ahring BK: Thermophilic anaerobic digestion of livestock waste: the effect of ammonia. Appl Microbiol Biot 1993, 38:560-564.

20. Angelidaki I, Ellegaard L, Ahring BK: A mathematical model for dynamic simulation of anaerobic digestion of complex substrates: focusing on ammonia inhibition. Biotechnol Bioeng 2004, 42:159-166.

21. Yen HW, Brune DE: Anaerobic co-digestion of algal sludge and waste paper to produce methane. Bioresource Technol 2007, 98:130-134.

22. Angelidaki l, Ahring BK: Effects of free long-chain fatty acids on thermophilic anaerobic digestion. Appl Microbiol Biot 1992, 37:808-812.

23. Biebl H: Fermentation of glycerol byClostridium pasteurianum- batch and continuous culture studies. J Ind Microbiol Microbiot 2001, 27:18-26.

24. El-Mashad HM, Zhang R: Biogas production from co-digestion of dairy manure and food waste. Bioresourse Technol 2010, 101:4021-4028.

25. Chen G, Zheng Z, Yang S, Fang C, Zou X, Zhang J: Improving conversion ofSpartina alterniflorainto biogas by co-digestion with cow feces. Fuel Process Technol 2010, 91:1416-1421

26. Lehtomaki A, Huttunen S, Rintala JA: Laboratory investigations of energy crops and crop residues with cow manure for methane production effect of crop to manure ratio. Resour Conserv Recy 2007, 51:591-609.

27. Regueiro L, Veiga P, Figueroa M, Alonso-Gutierrez J, Stams AJM, Lema JM, Carballa M: Relationship between microbial activity and microbial community structure in six full-scale anaerobic digesters. Microbiol Res 2012, 167:581-589.

28. Ike M, Inoue D, Miyano T, Liu TT, Sei K, Soda S, Kadoshin S: Microbial population dynamics during startup of a full-scale anaerobic digester treating industrial food waste in Koyoto eco-energy project. Bioresource Technol 2010, 101:3952-3957.

29. Van Velsen AFM: Adaptation of methanogenic sludge to high ammonianitrogen concentrations. Water Res 1979, 13:995-999.

30. Griffin ME, McMahon KD, Mackie Rl, Raskin L: Methanogenic population dynamics during start-up of anaerobic digesters treating municipal solid waste and biosolids. Biotechnol Bioeng 1998, 57:342-355

31. Raposo F, Borja R, Martín MA, Martín A, de la Rubia MA, Rincón B: Influence of inoculum to substrate ratio on the anaerobic digestion of sunflower oil cake in batch mode: process stability and kinetic evaluation. Chem Eng J 2009, 149:70-77.

32. Lins P, Reitschuler C, Illmer P: Development and evaluation of inocula combating high acetate concentrations during the start-up of an anaerobic digestion. Bioresource Technol 2012, 110:167-173.
33. Hansen $\mathrm{KH}$, Angelidaki I, Ahring BK: Anaerobic digestion of swine manure: inhibition by ammonia. Water Res 1998, 32:5-12.

34. Hashimoto AG: Ammonia inhibition of methanogenesis from cattle wastes. Agric Wastes 1986, 17:241-261.

35. Ma J, Carballa M, De Caveye PV, Verstraete W: Enhanced propionic acid degradation (EPAD) system: Proof of principle and feasibility. Water Res 2009, 43:3239-3248.

36. Gallert C, Winter J: Propionic acid accumulation and degradation during restart of a full scale anaerobic biowaste digester. Bioresource Technol 2008, 99:170-178.

37. Raes J, Korbel JO, Lercher MJ, vor Mering C, Bork P: Prediction of effective genome size in metagenomic samples. Genome Biol 2007, 8:19.

38. Wirth R, Kovacs E, Maróti G, Bagi Z, Rakhely G, Kovacs KL: Characterization of a biogas producing microbial community by short read next generation DNA sequencing. Biotechnol Biofuels 2012, 5:1-16.

39. Krause L, Diaz NN, Edwards RA, Gartemann K-H, Krömeke H, Neuwger H, Pühler A, Runte KJ, Schlüter A, Stoye J, Szczepanowski R, Tauch A, Goesmann A: Taxonomic composition and gene content of a methaneproducing microbial community isolated from a biogas reactor. J Biotech 2008, 136:91-101

40. Sundberg C, Al-Soud WA, Larsson M, Alm E, Yekta SS, Svensson BH, Sørensen SJ, Karlsson A: 454 pyrosequencing analyses of bacterial and archaeal richness in 21 full-scale biogas digesters. FEMS Microbiol Ecol 2013, 85:612-626.

41. Li A, Chu YN, Wang X, Ren L, Yu J, Liu X, Yan J, Zhang L: A pyrosequencingbased metagenomic study of methane-producing microbial community in solid-state biogas reactor. Biotechnol Biofuels 2013, 6:3.

42. Klocke M, Mähnerta P, Mundt K, Souidia K, Linke B: Microbial community analysis of a biogas-producing completely stirred tank reactor fed continuously with fodder beet silage as mono-substrate. Syst Appl Microbiol 2007, 30:139-151.

43. Rinke C, Schwientek P, Sczyrba A, Ivanova NN, Anderson IJ, Cheng J-F, Darling A, Malfatti S, Swan BK, Gies EA, Dodsworth JA, Hedlund BP, Tsiamis G, Sievert SM, Liu W-T, Eisen JA, Hallam SJ, Kyrpides NC, Stepanauskas R, Rubin EM, Hugenholtz P, Woyke T: Insights into the phylogeny and coding potential of microbial dark matter. Nature 2013, 499:431-437.

44. Li YF, Chen PH, Yu Z: Spatial and temporal variations of microbial community in a mixed plug-flow loop reactor fed with dairy manure. Microbial Biotechnol 2014. doi:10.1111/1751-7915.12125.

45. Pelletier E, Kreymeyer A, Bocs S, Rouy Z, Gyapay G, Chouari R, Riviere D, Ganesan A, Daegelen P, Sghir A, Cohen GN, Medigue C, Weissenbach J, Paslier DL: "Candidatus Cloacamonas acidaminovorans": genome sequence reconstruction provides a first glimpse of a new bacterial division. J Bacteriol 2008, 190:2572-2579.

46. Zakrzewski M, Goesmann A, Jaenicke S, Junemann S, Eikmeyer F, Szczepanowski R, Al-Soud WA, Sørensen S, Pühler A, Schluter A: Profiling the metabolically active community from a production scale biogas plant by means of high throughput metatranscriptome sequencing. J Biotechnol 2012, 158:248-258.

47. Schluter A, Bekel T, Diaz NN, Dondru M, Eichenlaub R, Gartemann KH, Krahn I, Krause L, Kromeke H, Kruse O, Mussgnug JH, Neuweger $H$, Niehaus K, Pühler A, Runte KJ, Szczepanowski R, Tauch A, Tilker A, Viehover P, Goesmann A: The metagenome of a biogas producing microbial community of a production scale biogas plant fermenter analyzed by the 454-pyrosequencing technology. J Biotechnol 2008, 136:77-90.

48. Kovács E, Wirth R, Maróti G, Bagi Z, Rákhely G, Kovács KL: Biogas production from protein-rich biomass: fed-batch anaerobic fermentation of casein and of pig blood and associated changes in microbial community composition. PLoS One 2013, 8:10.

49. Mclnerney MJ, Bryant MP, Hespell RB, Costerton JW: Syntrophomonas wolfeigen. nov. sp. nov., an anaerobic, syntrophic, fatty acid-oxidizing bacterium. Appl Environ Microbiol 1981, 41:1029-1039.

50. Sousa DZ, Smidt H, Alves M, Stams AJM: Ecophysiology of syntrophic communities that degrade saturated and unsaturated long-chain fatty acids. FEMS Microbiol Ecol 2009, 68:257-272.

51. Scholten JCM, Conrad R: Energetics of syntrophic propionate oxidation in defined batch and chemostat cocultures. Appl Environ Microbiol 2000, 66:2934-2942

52. Boone DR, Johnson RL, Liu Y: Diffusion of the interspecies electron carriers $\mathrm{H}(2)$ and formate in methanogenic ecosystems and its 
implications in the measurement of $\mathrm{K}(\mathrm{m})$ for $\mathrm{H}(2)$ or formate uptake. Appl Environ Microbiol 1989, 55:1735-1741.

53. Tabatabaeia M, Rahimc RA, Abdullahd N, Wrighte ADG, Shiraif Y, Sakaig K, Sulaimanh A, Hassan MA: Importance of the methanogenic Archaea populations in anaerobic wastewater treatments. Process Biochem 2010, 45:1214-1225.

54. Sun L, Müller B, Westerholm M, Schnürer A: Syntrophic acetate oxidation in industrial CSTR biogas digesters. J Biotechnol 2013, 171:39-44.

55. Karakashey D, Batstone DJ, Trably E, Angelidaki I: Acetate oxidation is the dominant methanogenic pathway from acetate in the absence of Methanosaetaceae. Appl Environ Microbiol 2006, 72:5138-5141.

56. Kröber M, Bekel T, Diaz NN, Goesmann A, Sebastian J: Phylogenetic characterization of a biogas plant microbial community integrating clone library 16S-rDNA sequences and metagenome sequence data obtained by 454-pyrosequencing. J Biotech 2009, 142:38-49.

57. Jaenicke S, Ander C, Bekel T, Bisdorf R, Dröge M, Gartemann K-H, Jünemann S, Kaiser O, Krause L, Tille F, Zakrzewski F, Pühler A, Schlüter A, Goesmann A: Comparative and joint analysis of two metagenomic datasets from a biogas fermenter obtained by 454-pyrosequencing. PLoS One 2011, 6:1.

58. Pilloni G, Granitsiotis MS, Engel M, Lueders T: Testing the limits of 454 pyrotag sequencing: reproducibility. Quantitative assessment and comparison to T-RFLP fingerprinting of aquifer microbes. PLoS One 2012 7:7

59. ISO 11465: Soil quality. Determination of dry matter and water content on a mass basis. Gravimetric method. 1993.

60. NS-EN 15935: European Standard method for the determination of the loss on ignition (LOI) of dry matter at $550^{\circ} \mathrm{C} .2012$.

61. ISO 10390: Soil quality. Determination of pH. 2005.

62. Norwegian Sequencing Centre. http://www.sequencing.uio.no

63. Schmieder R, Edwards R: Quality control and preprocessing of metagenomic datasets. Biogeosciences 2011, 27:863-864.

64. Schloss PD, Westcott SL, Ryabin T, Hall JR, Hartmann M, Hollister EB, Lesniewski RA, Oakley BB, Parks DH, Robinson CJ, Sahl JW, Stres B, Thallinger GG, Van Horn DJ, Weber CF: Introducing mothur: open-source, platform-independent, community-supported software for describing and comparing microbial communities. Appl Environ Microbiol 2009, 75:7537-7541.

65. Niu BF, Fu LM, Sun SL, Li WZ: Artificial and natural duplicates in pyrosequencing reads of metagenomic data. BMC Bioinformat 2010, 11:187-198

66. BIOPORTAL.UIO.NO. http://www.mn.uio.no/ibv/bioportal/index.html.

67. STRING - Known and Predicted Protein-Protein Interactions. http://string-db.org/.

68. Altschul SF, Gish W, Miller W, Myers EW, Lipman DJ: Basic local alignment search tool. J Mol Biol 1990, 215:403-410

69. Beszteri B, Temperton B, Frickenhaus S, Giovannoni SJ: Average genome size: a potential source of bias in comparative metagenomics. ISME $J$ 2010, 4:1075-1077.

70. Huson DH, Auch AF, Qi J, Schuster SC: MEGAN analysis of metagenomic data. Genome Res 2007, 17:377-386.

71. Huson DH, Mitra S, Ruscheweyh HJ, Weber N, Schuster SC: Integrative analysis of environmental sequences using MEGAN4. Genome Res 2011, 21:1552-1560.

72. The R Project for Statistical Computing. http://www.r-project.org.

73. Havelsrud OE, Haverkamp THA, Kristensen T, Jakobsen K, Rike AG: Metagenomic and geochemical characterization of pockmarked sediments overlaying the troll petroleum reservoir in the North Sea. BMC Microbiol 2012, 12:203

74. Meyer F, Paarmann D, D'Souza M, Olson R, Glass EM, Kubal M, Paczian T, Rodriguez A, Stevens R, Wilke A, Wilkening J, Edwards RA: The metagenomics RAST server - a public resource for the automatic phylogenetic and functional analysis of metagenomes. BMC Bioinformat 2008, 9:386

75. MG-RAST. Metagenomic Analysis Server. http://metagenomics.anl.gov/.

doi:10.1186/s13068-014-0146-2

Cite this article as: Solli et al: A metagenomic study of the microbial communities in four parallel biogas reactors. Biotechnology for Biofuels 2014 7:146.

\section{Submit your next manuscript to BioMed Central and take full advantage of:}

- Convenient online submission

- Thorough peer review

- No space constraints or color figure charges

- Immediate publication on acceptance

- Inclusion in PubMed, CAS, Scopus and Google Scholar

- Research which is freely available for redistribution 